\title{
Research on Load Characteristic of Electrothermal Film Heating Community
}

\author{
Lei Yang1, Tianzong Liu², Xiaoguang Wang1, Jin He1, Xiaobo Song1 \\ ${ }^{1}$ Electric Power Research Institute of Tianjin Electric Power Corporation, Tianjin, China \\ ${ }^{2}$ State Grid Tianjin Dongli Electric Power Company, Tianjin, China \\ Email: hhhheee1@163.com
}

How to cite this paper: Yang, L., Liu, T.Z., Wang, X.G., He, J. and Song, X.B. (2017) Research on Load Characteristic of Electrothermal Film Heating Community. Energy and Power Engineering, 9, 155-161. https://doi.org/10.4236/epe.2017.94B019

Received: January 22, 2017

Accepted: March 30, 2017

Published: April 6, 2017

\begin{abstract}
In this paper, a case study of an electrothermal film heating community in Tianjin is carried out, in which the winter load characteristic and electricity use law are analyzed. In this community, every household installs two watthour meters, one of which is only used to measure the electrothermal heating power, so the interference factors are eliminated. The main factors influencing the residents' power consumption are summarized, and a method for estimating the thermal load of the residents is given. The conclusions can provide important reference to generalize the electric heating technology.
\end{abstract}

\section{Keywords}

Load Characteristic, Electrothermal Film Heating

\section{Introduction}

As one important aspect of power substitution, the electric heating technology is widely applied in communities. The study of the winter load characteristics of the electric heating residential communities will provide reference for reasonable selection of distribution equipment.

Electric heating technology has a variety of types: electrothermal heating film [1], heating-storage electric boiler [2], heating cable [3], carbon-fiber electric heating board [4], and so on. In recent years, the electrothermal film heating is applied more widely in communities, because of its high thermal efficiency, convenient installation and other advantages. For the electrothermal film heating of a typical community in Tianjin, this paper gives the change rule of its power load characteristic, analyzes the main factors of impacting residents' power consumption, and puts forward a method to estimate the heat load. 


\section{Load Characteristic of the Electrothermal Film Heating Community}

\subsection{Introduction of the Selected Community}

The community which is studied as a typical example was built in 2001. It has been running for more than 15 years. There are 5 north-south residential buildings in total, and each building has 6 storeys. With a total construction area of $27,400 \mathrm{~m}^{2}$, the community contains 275 households, all of which have installed electrothermal film heating equipment.

\subsection{Characteristic and Change Rule of the Winter Heating Load}

The electricity of the community is supplied by 6 distribution transformers. From September 1, 2014 to March 31, 2015, the power data of each transformer is collected by the electric data acquisition system, and the maximum power and its time of occurrence during this period are obtained, as illustrated in Table 1. The system records 96 power values every day (every 15 minutes from 0:00).

The total capacity of the above 6 transformers is $2760 \mathrm{k} \cdot \mathrm{VA}$, and the total construction area of 5 buildings is $27,400 \mathrm{~m}^{2}$, so the actual power configuration of the district is $100.73 \mathrm{~W} / \mathrm{m}^{2}$, which has a large margin.

It is proved that all daily load curves of 6transformer districts are similar, and the variation of load power is roughly the same. Three of them are arbitrarily chosen to plot the average load curves (here Number 1, 3, and 6 are taken for examples). The plotting method is that: for each day of a month, the average value of the same time is used as one point on the curve, and in this way all 96 points, which finally form a curve, are plotted. According to the actual situation in Tianjin, December and January is the coldest months, in which the load curves have been plotted with the above method. The average load rate of Figure 1 changes in the $10 \%-20 \%$, and the average load rate of Figure 2 changes in $6 \%$ 15\%. In Figure 3 the average load rate changes between 5\%-11\%, so the 6 distribution transformers in the community work at low load rate. In addition, the time of the higher load rate appears at 8:00-9:00 in the morning and 21:00-22:00 in the evening, and the wave crests present "one small one big" shape, as shown in Figures 1-3.

Table 1. Actual load of the electrothermal film heating community.

\begin{tabular}{|c|c|c|c|c|c|}
\hline $\begin{array}{l}\text { District } \\
\text { Number }\end{array}$ & $\begin{array}{c}\text { Rated } \\
\text { Capacity } \\
(\mathrm{kVA})\end{array}$ & $\begin{array}{c}\text { Maximum } \\
\text { Power } \\
(\mathrm{kW})\end{array}$ & \multicolumn{2}{|c|}{$\begin{array}{c}\text { Time of } \\
\text { Maximum Power }\end{array}$} & $\begin{array}{l}\text { Maximum } \\
\text { Load Rate }\end{array}$ \\
\hline 1 & 500 & 142.46 & 2014.12 .10 & $20: 30$ & $28.5 \%$ \\
\hline 2 & 500 & 118.18 & 2014.12 .21 & $20: 45$ & $23.6 \%$ \\
\hline 3 & 250 & 53.2 & 2014.12 .13 & $21: 15$ & $21.3 \%$ \\
\hline 4 & 250 & 60.88 & 2014.01.27 & $21: 00$ & $24.4 \%$ \\
\hline 5 & 630 & 161.74 & 2015.03 .13 & $11: 15$ & $25.7 \%$ \\
\hline 6 & 630 & 90.9 & 2014.12 .05 & $22: 00$ & $14.4 \%$ \\
\hline
\end{tabular}




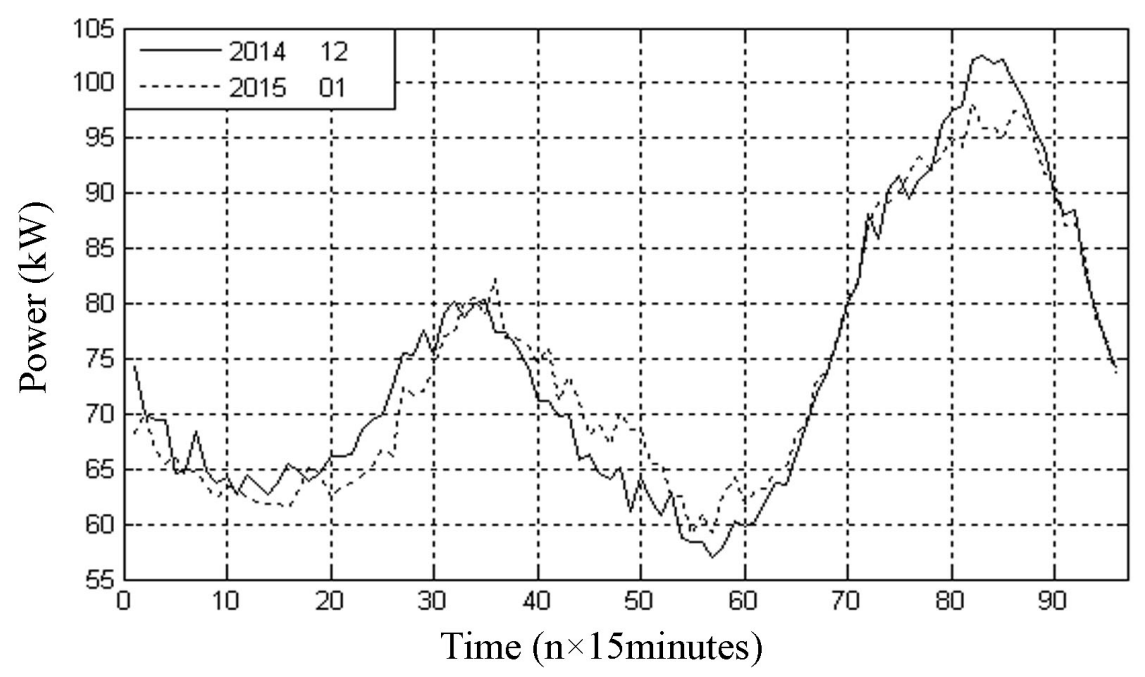

Figure 1. Daily average load curve of the Number 1 transformer district.

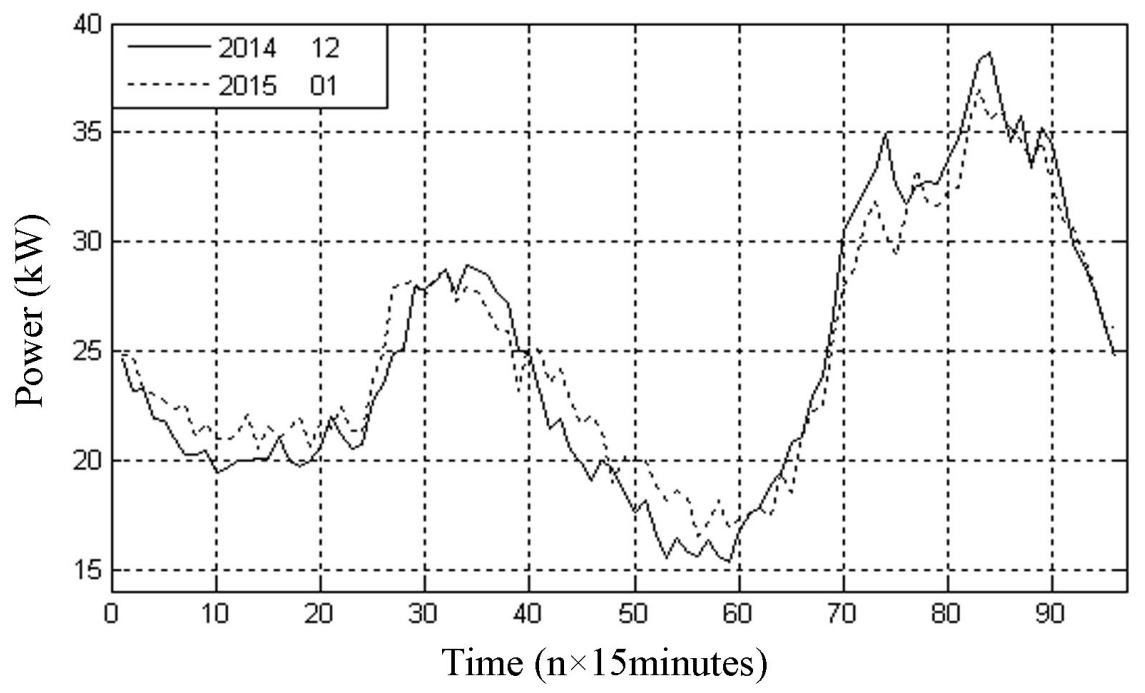

Figure 2. Daily average load curve of the Number 3 transformer district.

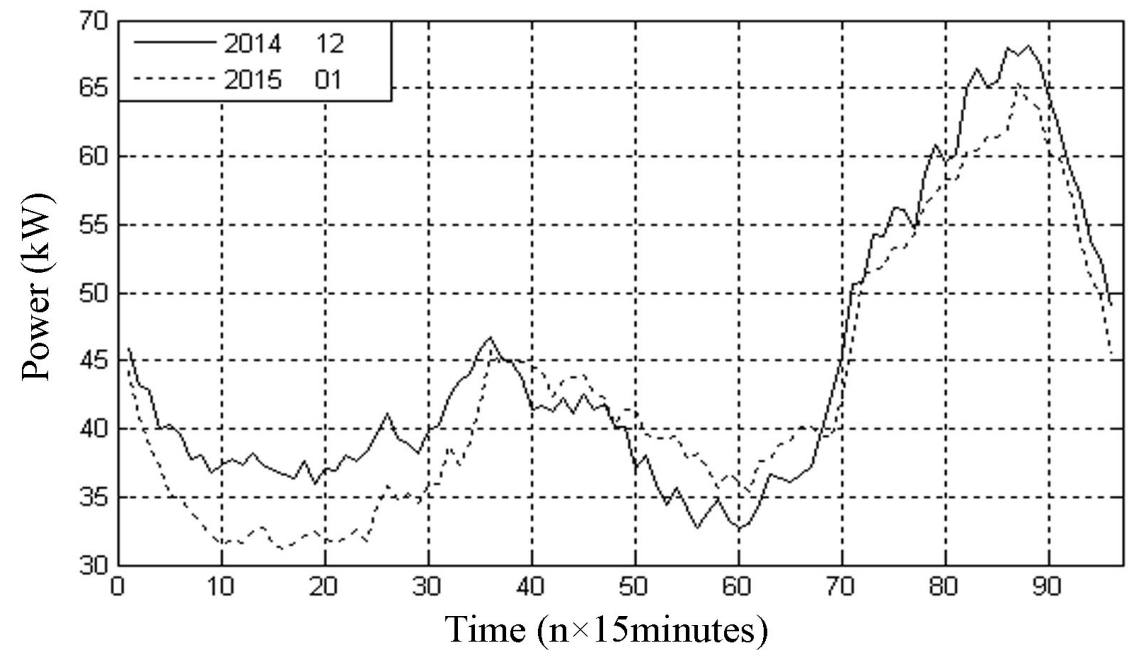

Figure 3. Daily average load curve of the Number 6 transformer district. 


\subsection{Electric Load Characteristics of the Community}

Some electric load characteristics of the electric heating community can be concluded from this case study, as follows:

1) For all the distribution transformers in the heating season, the maximum load rate is less than $30 \%$, and the configuration of the distribution equipment is $100 \mathrm{~W} / \mathrm{m}^{2}$, which actually has a large margin.

2) The maximum load rate mostly occurred at 20:00-22:00 in the evening of December, so we should strengthen the monitoring of the transformer in that period.

3) From the above analysis, for the new community of heating film, the recommended power capacity is $65-90 \mathrm{~W} / \mathrm{m}^{2}$, which is the economy selection for distribution transformers.

\subsection{Analysis of the Residential Power Consumption}

Every household in the community installs two watt-hour meters, as shown in Figure 4. One is only used to measure the power consumption of electrothermal film heating, and the other is used to measure other daily electricity consumption of residents, thereby excluding the impact of interfering factors.

For users in Unit 1 and Unit 2 of No.1 Building in this community, the data about electrothermal film heating information, a total of 27 residents' heating electricity consumption which is from September 1, 2014 to March 30, 2015, is extracted through SG186 system and Electric Energy Data Acquisition System. Ruling out 2 households without intelligent watt-hour meters and 5 uninhabited households-if the electricity consumption is always zero, it has been judged to be uninhabited after field verification-we obtain 20 valid samples, as shown in Table 2 . The average daily electricity consumption of them is $0.072 \mathrm{k} \cdot \mathrm{Wh} /\left(\mathrm{m}^{2} \cdot\right.$ day $)$.

From September 1, 2014 to March 30, 2015 (the main heating period), in the 20 samples, the maximum electricity consumption is $2339 \mathrm{k} \cdot \mathrm{Wh}$ and the minimum is $167 \mathrm{k} \cdot \mathrm{Wh}$, so there is a differential of 14 .

According to Equation (1)

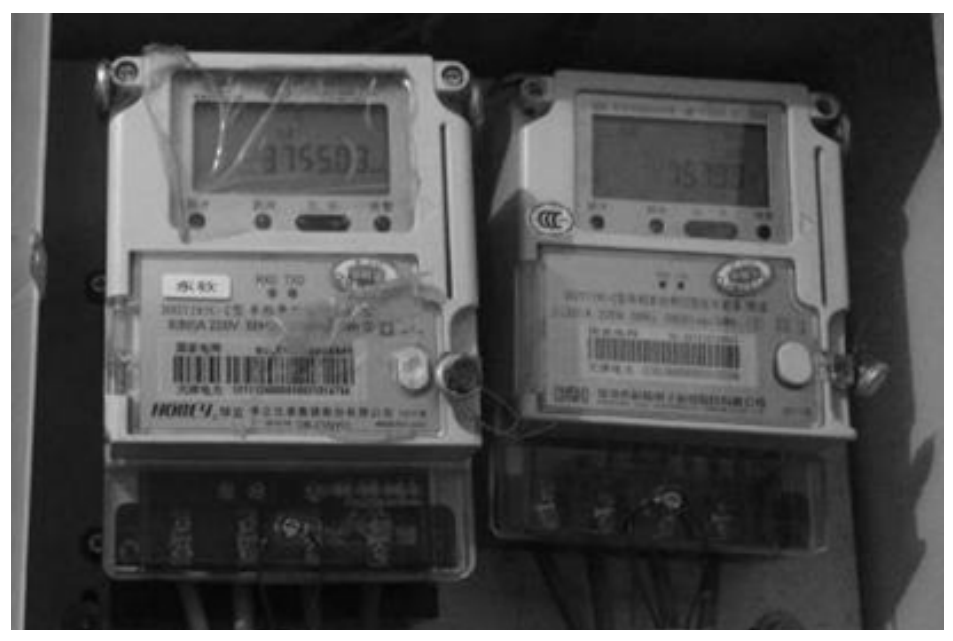

Figure 4. The two watt-hour meters installed in a household. 


$$
P=\frac{\sum_{i=1}^{n} Q_{i}}{n N H},
$$

the average load is calculated. $Q_{i}$ is each household electricity consumption in the heating seasons, $n$ is the valid sample number, $N$ is the total number of days (here take 211 days), $H$ is converted hours (here take 12 hours), $P=475.5 \mathrm{~W}$ (if $H$ is $24, P=237.8 \mathrm{~W}$ ), the details of household average load are shown in Table 2.

\section{The Power Capacity Allocation of Residents' Electrothermal Film Heating}

\subsection{The Main Factors Influencing Power Consumption}

It is concluded that the main factors that affect the electricity consumption of local residents' heating are as follows:

First of all, the floor space of the apartment is a factor that influences power consumption. The larger the floor space is, the more the electricity consumption is. The duplex apartment which is on two floors is a concrete example.

Secondly, the floor and the location of a room is another factor. For instance,

Table 2. Electric heating power consumption of the selected 20 residents.

\begin{tabular}{|c|c|c|c|c|}
\hline Number & $\begin{array}{l}\text { Energy } \\
(\mathrm{kWh})\end{array}$ & $\begin{array}{l}\text { Area } \\
\left(\mathrm{m}^{2}\right)\end{array}$ & $\begin{array}{c}\text { Daily consumption } \\
{\left[\mathrm{kWh} /\left(\mathrm{m}^{2} \cdot \text { day }\right)\right]}\end{array}$ & $\begin{array}{c}\text { Average power } \\
\text { (W) }\end{array}$ \\
\hline 1 & 734.74 & 82.45 & 0.04 & 290.2 \\
\hline 2 & 1178.12 & 60.56 & 0.09 & 465.3 \\
\hline 3 & 1062.01 & 85.55 & 0.06 & 419.4 \\
\hline 4 & 2339.06 & 82.45 & 0.13 & 923.8 \\
\hline 5 & 940.81 & 85.55 & 0.05 & 371.6 \\
\hline 6 & 2129.13 & 82.45 & 0.12 & 840.9 \\
\hline 7 & 603.69 & 85.55 & 0.03 & 238.4 \\
\hline 8 & 2287.39 & 82.45 & 0.13 & 903.4 \\
\hline 9 & 1174.13 & 85.55 & 0.07 & 463.7 \\
\hline 10 & 299.43 & 60.56 & 0.02 & 118.3 \\
\hline 11 & 850.17 & 85.55 & 0.05 & 335.8 \\
\hline 12 & 1571.59 & 102.22 & 0.07 & 620.7 \\
\hline 13 & 167.16 & 129.87 & 0.01 & 66.0 \\
\hline 14 & 1891.3 & 85.55 & 0.10 & 747.0 \\
\hline 15 & 314.46 & 77.8 & 0.02 & 124.2 \\
\hline 16 & 539.84 & 85.5 & 0.03 & 213.2 \\
\hline 17 & 560.44 & 60.56 & 0.04 & 221.3 \\
\hline 18 & 1825.07 & 77.8 & 0.11 & 720.8 \\
\hline 19 & 1390.51 & 85.55 & 0.08 & 549.2 \\
\hline 20 & 2220.55 & 60.56 & 0.17 & 877.0 \\
\hline Average & 1203.980 & 82.204 & 0.072 & 475.5 \\
\hline
\end{tabular}


on the ground floor, heating film is only installed on the top wall, but not on the floor. Another example is that the heating time of a room with good lighting is shorter than sunless ones.

The third factor is the occupancy rate. If a building's occupancy rate is low, the residents' consumption will be increased because of the overall effect. According to the Four Step of Energy-saving Standards, only exterior walls of the whole building have thermal insulation materials.

The last one is the user's own reasons. For each individual member of the community, tolerance to cold is different (e.g., for the elderly users, indoor temperature is always in the high range with the heating equipment always on). In bathrooms and other unfrequently used rooms, some people are accustomed to keeping the heating switch off. Data also shows that most people turn on the electrothermal film heating equipment in mid-November and the closing time is in late March, only a minority of users open early or close late.

\subsection{A Method for Estimating the Thermal Load}

Using the following estimation method, we considers temperature, area, occupancy rate, and the influence of habits and other factors when calculating thermal load of electrothermal film heating. Therefore, it is more reasonable to meet the demand of residents.

1) Temperature. Here it is determined by the temperature of the local region in recent 5 years. Temperature data of the coldest 15 days in the coldest month of each year were collected to obtain their average, which is taken as outdoor calculation temperature. Therefore, it is considered under harsh conditions.

2) Area. It mainly refers to the area of wall and floor. Meanwhile the influence of different building materials should be considered.

3) Occupancy rate. Our investigation indicates that as for the same electrothermal film heating, the community with a low occupancy needs greater heat load than ones with a high occupancy rate. The reason is that whether neighbor's heating equipment is turned on will have the effect of heat dissipation.

4) Use habits. Through the research we found that for different groups of people, the demand for thermal load is also different, so in the calculation the differences in the degree of acceptance of the heat and cold should be taken into account.

Based on the above four factors, the estimation formula of the heating load is put forward:

$$
P=S K\left(t-t_{w}\right)=\left(\eta S_{0}+\sum S_{i}+\mu \sum S_{i}\right) K\left(t_{0}+t_{1}+t_{w}\right)
$$

The meaning of symbols in Equation (2) and the method of determining the parameters are as follows:

$P$ is the required heating power, its unit is $\mathrm{W}$.

$S$ is the equivalent total area, its unit is $\mathrm{m}^{2}$.

$S_{0}$ is the construction area. According to practical experience, heat load in the rooms with good lighting is less than that in sunless rooms, therefore it should 
be multiplied by the coefficient $\eta$ which is $0.85-1.1$.

$S_{1}$ is the total area of walls which are in direct contact with the outside air, $S_{1}=$ $\Sigma S_{i}, S_{i}$ represents the area of each wall.

Assuming that a building has a certain occupancy rate, i.e., whether each apartment is inhabited or not is known, the total area of walls between calculated and inhabited rooms can be determined. Because the heat quantity given off from these walls is smaller than those in direct contact with the outside air, so it should be multiplied by the equivalent coefficient $\mu, S_{2}=\mu \Sigma S_{i}$

In summary, the equivalent total area $S$ is the sum of the three parts.

$K$ is equivalent heat transfer coefficient, its unit is $\mathrm{W} /\left(\mathrm{m}^{2} \cdot{ }^{\circ} \mathrm{C}\right)$. According to different building materials, it is directly determined with reference to the relevant technical standards.

$t$ is indoor calculation temperature, considering use habits, its unit is ${ }^{\circ} \mathrm{C} . t=$ $t_{0}+t_{1}, t_{0}$ is indoor calculation temperature. Considering different habits of the residents, for people who prefer warmer weather, taking the elderly for instance, $t_{1}=1$ to $2^{\circ} \mathrm{C}$, while for people who like cold weather, take $t_{1}=-1$ to $-2^{\circ} \mathrm{C}$, and $t_{1}=0^{\circ} \mathrm{C}$ in general.

$t_{w}$ is outdoor temperature, its unit is ${ }^{\circ} \mathrm{C}$.

Finally, putting the data into the formula, we get the value of heat load for electrothermal film heating, which provides a more accurate estimate.

\section{Conclusions}

In this article, load characteristic of electrothermal film heating community has been researched by case study. The load curves show "one small one big" shape.

Excluding interference factor of the residents' power consumption for daily life, we obtain electric law of electrothermal film heating from residents' actual usage. The recommended power capacity for electrothermal heating is $65-90$ $\mathrm{W} / \mathrm{m}^{2}$, which is more reasonable for distribution transformer selection.

The main factors that affect the electricity consumption of local residents' heating are area, location, occupancy rate, and user's own customs. Considering these factors, we provide an estimation method of calculating thermal load, which is a more accurate and economy estimate.

This paper can provide important reference to generalize the electric heating technology.

\section{References}

[1] Zhao, J. and Song, S. (2010) Application of Electrothemal Membrane Heating in Electricity Market. North China Electric Power, 9, 38-40.

[2] Li, Y. and Xie, K. (2009) Application Analysis on Electric Boiler with Thermal Technology. Heibei Electric Power, 28, 41-45.

[3] Li, Y. (2009) Application of Heating Cable in Civil Architecture. Shanxi Architecture, 35, 203-204.

[4] Li, Y., Zhao, Y., He, C., Yan, Y. and Yu, X. (2014) Application of Electric Carbon Crystal Warming Board for Seedings Culture of Cucumber in Greenhouse in Winter. Journal of China Agricultural University, 19, 126-133. 
Submit or recommend next manuscript to SCIRP and we will provide best service for you:

Accepting pre-submission inquiries through Email, Facebook, LinkedIn, Twitter, etc. A wide selection of journals (inclusive of 9 subjects, more than 200 journals)

Providing 24-hour high-quality service

User-friendly online submission system

Fair and swift peer-review system

Efficient typesetting and proofreading procedure

Display of the result of downloads and visits, as well as the number of cited articles Maximum dissemination of your research work

Submit your manuscript at: http://papersubmission.scirp.org/

Or contact epe@scirp.org 